Insurance Markets with Differential Information

\author{
S. Hun Seog [석승훈] \\ Graduate School of Management, KAIST (KGSM) \\ 207-43 Cheongryangri-Dong, Dongdaemun-Gu, \\ Seoul, 130-722, KOREA \\ Email: seogsh@kgsm.kaist.ac.kr
}

Phone: +82-2-958-3527

Fax: $+82-2-958-3604$

This Version: May 2006 


\title{
Insurance Markets with Differential Information
}

\begin{abstract}
This paper attempts to understand the outcomes when each party of the insurance contracts simultaneously has superior information to the other. We decompose the risk of a policyholder into a general risk and a specific risk. We assume that policyholders have superior information about specific risks while insurers have superior information about general risks. When each risk can be either high or low, we find that low-general-risk policyholders purchase insurance, while highgeneral-risk policyholders are self-insured. Among the low-general-risk policyholders, high-specific-risk policyholders purchase full insurance, while low-specific-risk policyholders purchase partial insurance. When insurers can strategically use technology to publicize their information, efficiency is unambiguously improved since high-general-risk policyholders purchase insurance. A clientele relationship is also found: Low-general-risk policyholders purchase insurance from insurers that do not publicize information, while high-general-risk policyholders purchase from insurers that publicize information. Main results still hold when the model is extended to multiplerisk cases.
\end{abstract}

Keywords: double-sided adverse selection, publicizing information, clientele relationship

JEL Classification: G220, D820 
Insurance Markets with Differential Information

\section{Introduction}

In standard adverse selection models, policyholders are considered to possess superior information about risks to insurance firms (Rothschild and Stiglitz, 1976; Dionne, Doherty, and Fombaron, 2000 and references therein). On the other hand, it is also true that insurance firms also possess superior information about some risks to policyholders. This case is investigated only recently in Villeneuve $(2000,2005)$. Different approaches lead to significantly different outcomes. In the standard policyholder-sided adverse selection model, high risk policyholders are fully insured and low risk policyholders are not fully insured. In the insurer-sided adverse selection model, high risk policyholders are not fully insured while low risk policyholders are fully insured.

In reality, each party of an insurance contract may have superior information about some part of risks to the other. For example, policyholders have superior information about whether or not they are smokers, but health insurers may have superior information about how smoking affects the health condition of a policyholder, or better understanding about the results of a health examination. Policyholders have superior information about their own driving habits, while insurers may have superior information about the mechanical problems of automobile brands and accident risks of diverse areas.

These observations imply that the consideration of double-sided adverse selection will provide a more realistic understanding of insurance markets. This paper attempts to understand the outcomes when each party of the insurance contracts simultaneously has superior information to the other. We decompose the risk (probability of loss) of a policyholder into a general risk and a specific risk. We assume that policyholders have superior information about specific risks while insurers have superior information about general risks. Based on this assumption, we derive the equilibrium outcomes in competitive insurance markets where insurers try to signal their information, as well as they need to screen policyholders.

Our findings are as follows. When each risk can be either high or low, lowgeneral-risk policyholders purchase insurance, while high-general-risk policyholders are self-insured. Among the low-general-risk policyholders, high-specific-risk policyholders purchase full insurance, while low-specific-risk policyholders purchase partial insurance. We also investigate the role of publicizing information. When 
insurers can strategically use technology to publicize their information, efficiency is unambiguously improved, since high-general-risk policyholders purchase insurance. We find a clientele relationship: Low-general-risk policyholders purchase insurance from insurers that do not publicize information, while high-general-risk policyholders purchase from insurers that publicize information.

When our model is extended to multiple-risk cases, the lowest-general-risk policyholders purchase insurance, while other policyholders are self-insured. Among the lowest-general-risk policyholders, the highest-specific-risk policyholders purchase full insurance, while other policyholders purchase partial insurance. When insurers can strategically use technology to publicize their information, a clientele relationship still holds: The lowest-general-risk policyholders purchase insurance from insurers that do not publicize information, while other policyholders purchase from insurers that publicize information. As a result, efficiency is improved, since high-general-risk policyholders purchase insurance.

One interesting implication of our results is that the relationship between risks and insurance demands is not in one direction, unlike in the standard adverse selection literature. For example, a risk may purchase insurance while higher as well as lower risks may be self-, or less- insured. In empirical research, no correlations between risks and insurance demands are considered as evidence of the non-existence of adverse selection (Chiappori, 2000). However, our result implies that this is not necessarily the case. When a one-sided adverse selection problem is to be investigated, the othersided adverse selection problem should be controlled.

The rest of the paper is composed as follows. Section II describes the model. Section III discusses and summarizes the results of one-sided adverse selection cases. Section IV derives the results of a double-sided adverse selection case. Section V discusses the role of publicizing information in resolving adverse selection problems. Section VI considers a multiple-risk case. Section VII concludes.

\section{The Model}

We consider a competitive insurance market in which (potential) policyholders face a fixed insurable loss of D. Policyholders are expected utility maximizers and insurers are risk neutral. Policyholders are homogeneous except for their risk types, $\mathrm{T}$. We assume that the risk of a policyholder can be decomposed into two risks, called a general risk $\left(T_{1}\right)$ and a specific risk $\left(T_{2}\right)$, respectively. We will focus on the case in which insurers can only observe policyholders' general risks, while policyholders can only observe their own specific risks. As an example, policyholders have superior 
information about whether or not they are smokers, but health insurers may have superior information about how smoking affects the health condition of a policyholder, or better understanding on the results of health examination. In another example, policyholders have superior information about their own driving habits, while insurers may have superior information about the mechanical problems of automobile brands and road safety.

For simplicity, we assume that each of two risks $T_{i}$ can be high $(H)$ or low $(L)$. The risk decomposition allows to express type $\mathrm{T}$ as $\mathrm{T}=\mathrm{T}_{1} \mathrm{~T}_{2}$, so that there are four risk types: $\mathrm{T}=\mathrm{HH}, \mathrm{HL}, \mathrm{LH}$, and LL. The risk, or the probability of loss, of type $\mathrm{T}$ is denoted by $\mathrm{p}_{\mathrm{T}}$. We assume that $\mathrm{p}_{\mathrm{T}}$ is determined as the sum of two risks: $\mathrm{p}_{\mathrm{T}}=\mathrm{q}_{\mathrm{T} 1}+\mathrm{r}_{\mathrm{T} 2}$, where $T_{i}=H, L, q_{H}>q_{L}$, and $r_{H}>r_{L}$. We further assume that a policyholder has high general (specific) risk with probability $a(b)$, a priori. Let us denote $\mathrm{Q}$ and $\mathrm{R}$ for the ex ante expected general and specific risks of a policyholder, respectively: $Q=a_{H}+(1$ a) $q_{L}, R=b r_{H}+(1-b) r_{L} . \quad P$ denotes the ex ante expected risk: $P=Q+R . \quad$ Finally, we define $\mathrm{P}_{\mathrm{T}_{1}}=\mathrm{q}_{\mathrm{T} 1}+\mathrm{R}$, and $\mathrm{P}_{\mathrm{T}_{2}}=\mathrm{Q}+\mathrm{r}_{\mathrm{T}_{2}}$.

Let us denote $C_{i}=\left(\alpha_{i}, \beta_{i}\right)=$ (premium, gross indemnity) for the insurance contracts offered by insurers to type i-policyholders. When a type j-policyholder purchases $C_{i}$, his expected utility is expressed as $V\left(C_{i}: j\right)=p_{j} U\left(W-D-\alpha_{i}+\beta_{i}\right)+(1-$ $\left.p_{\mathrm{j}}\right) \mathrm{U}\left(\mathrm{W}-\alpha_{\mathrm{i}}\right)$, where $\mathrm{U}($.$) is a von Neumann-Morgenstern utility function. The$ expected profit of an insurer that sells $C_{i}$ to a type $j$-policyholder is expressed as $\pi\left(C_{i}: j\right)$ $=\alpha_{i}-p_{j} \beta_{i}$. For notational simplicity, define $V\left(C_{i}\right)=V\left(C_{i}: i\right)$ and $\pi\left(C_{i}\right)=\pi\left(C_{i}: i\right)$.

\section{Notations:}

Loss size $=\mathrm{D}$

Policyholder's type: $\mathrm{T} \equiv \mathrm{T}_{1} \mathrm{~T}_{2}=\mathrm{HH}, \mathrm{HL}, \mathrm{LH}, \mathrm{LL}$

$\mathrm{T}_{1}$ : general type: general risk $=\mathrm{q}$

$\mathrm{T}_{2}$ : specific type: specific risk $=\mathrm{r}$

$\mathrm{T}_{1}$ and $\mathrm{T}_{2}$ are independent.

The probability of loss of type $T=p_{T}=q_{T 1}+r_{T 2}$, where $T_{i}=H, L: q_{H}>q_{L}, r_{H}>r_{L}$. $\mathrm{a}=$ prior prob. of $\mathrm{q}_{\mathrm{H}}$

$\mathrm{b}=$ prior prob. of $\mathrm{r}_{\mathrm{H}}$

$\mathrm{Q}=\mathrm{aq}_{\mathrm{H}}+(1-\mathrm{a}) \mathrm{q}_{\mathrm{L}}$

$\mathrm{R}=\mathrm{br}_{\mathrm{H}}+(1-\mathrm{b}) \mathrm{r}_{\mathrm{L}}$

$\mathrm{P}=\mathrm{Q}+\mathrm{R}$ : average over $\mathrm{q}$ and $\mathrm{r}$

$\mathrm{P}_{\mathrm{T} 1}=\mathrm{q}_{\mathrm{T} 1}+\mathrm{R}$; average over $\mathrm{r}$ 
$\mathrm{P}_{\mathrm{T} 2}=\mathrm{Q}+\mathrm{r}_{\mathrm{T} 2}$ : average over $\mathrm{q}$

Policyholders observe their own $\mathrm{T}_{2}$, not $\mathrm{T}_{1}$.

Insurers observe $T_{1}$ of each policyholder, not $T_{2}$.

A competitive market is assumed.

$\mathrm{C}_{\mathrm{i}}=\left(\alpha_{\mathrm{i}}, \beta_{\mathrm{i}}\right)=$ (premium, gross indemnity) for type i-policyholders

$\mathrm{V}\left(\mathrm{C}_{\mathrm{i}}: \mathrm{j}\right)=\mathrm{p}_{\mathrm{j}} \mathrm{U}\left(\mathrm{W}-\mathrm{D}-\alpha_{\mathrm{i}}+\beta_{\mathrm{i}}\right)+\left(1-\mathrm{p}_{\mathrm{j}}\right) \mathrm{U}\left(\mathrm{W}-\alpha_{\mathrm{i}}\right)$; the expected utility of a type $\mathrm{j}$ policyholder when he purchases $\mathrm{C}_{\mathrm{i}}$.

$\mathrm{V}\left(\mathrm{C}_{\mathrm{i}}\right)=\mathrm{V}\left(\mathrm{C}_{\mathrm{i}}: \mathrm{i}\right)$.

$\pi\left(C_{i}: j\right)=\alpha_{i}-p_{j} \beta_{i}$

$\pi\left(\mathrm{C}_{\mathrm{i}}\right)=\pi\left(\mathrm{C}_{\mathrm{i}}: \mathrm{i}\right)$

\section{One-Sided Adverse Selection}

If there is no information asymmetry, the competitive insurance market will maximize the policyholder's expected utility, given the expected profits of insurers are nonnegative. An insurer will solve the following program.

Program 1 [No adverse selection]:

$\operatorname{Max}_{\{\mathrm{CT}\}} \mathrm{V}\left(\mathrm{C}_{\mathrm{T}}\right)=\mathrm{p}_{\mathrm{T}} \mathrm{U}\left(\mathrm{W}-\mathrm{D}-\alpha_{\mathrm{T}}+\beta_{\mathrm{T}}\right)+\left(1-\mathrm{p}_{\mathrm{T}}\right) \mathrm{U}\left(\mathrm{W}-\alpha_{\mathrm{T}}\right)$

s.t. $\pi\left(\mathrm{C}_{\mathrm{T}}\right)=\alpha_{\mathrm{T}}-\mathrm{p}_{\mathrm{T}} \beta_{\mathrm{T}} \geq 0$

It is well known from the existing literature that the equilibrium contract for type $\mathrm{T}$ is $\mathrm{C}_{\mathrm{T}}=\left(\mathrm{p}_{\mathrm{T}} \mathrm{D}, \mathrm{D}\right)$. Each policyholder is fully insured and the expected profit of an insurer is zero.

When policyholders can observe both their own $\mathrm{T}_{1}$ and $\mathrm{T}_{2}$, while insurers can only observe $T_{1}$ of each policyholder, the situation corresponds to the case of Rothschild and Stiglitz (1976), given $T_{1}$. No pooling equilibrium is possible. In a separating equilibrium, contracts $\left\{\mathrm{C}^{\mathrm{P}}{ }_{\mathrm{iH}}, \mathrm{C}^{\mathrm{P}}{ }_{\mathrm{iL}}\right\}$ solve the following program.

Program 2 [Policyholder-sided adverse selection]:

Given $\mathrm{T}_{1}=\mathrm{i}$;

$\operatorname{Max}_{\{\mathrm{CiH}, \mathrm{CiL}\}} \mathrm{V}\left(\mathrm{C}_{\mathrm{iL}}\right)=\mathrm{p}_{\mathrm{iL}} \mathrm{U}\left(\mathrm{W}-\mathrm{D}-\alpha_{\mathrm{iL}}+\beta_{\mathrm{iL}}\right)+\left(1-\mathrm{p}_{\mathrm{iL}}\right) \mathrm{U}\left(\mathrm{W}-\alpha_{\mathrm{iL}}\right)$

s.t. $\quad \pi\left(C_{i k}\right)=\alpha_{i k}-p_{i k} \beta_{i k} \geq 0$, for $k=H, L$.

$\mathrm{V}\left(\mathrm{C}_{\mathrm{ik}}\right) \geq \mathrm{V}\left(\mathrm{C}_{\mathrm{im}}\right.$ : ik) for $\mathrm{k}, \mathrm{m}=\mathrm{H}, \mathrm{L}$, and $\mathrm{k} \neq \mathrm{m}$. ${ }^{1}$

\footnotetext{
${ }^{1}$ In detail, the constraints are:
} 
The first set of constraints describes the participation of insurers. The second set of constraints describes the self-selection for policyholders regarding $\mathrm{T}_{2}$. Equilibrium outcomes are well known from Rothschild and Stiglitz (1976). In an separating equilibrium, if it exists, the following is obtained:

$\mathrm{C}^{\mathrm{P}}{ }_{\mathrm{iH}}=\left(\mathrm{p}_{\mathrm{iH}} \mathrm{D}, \mathrm{D}\right), \mathrm{C}_{\mathrm{iL}}^{\mathrm{P}}=\left(\mathrm{p}_{\mathrm{iL}} \mathrm{tD}, \mathrm{tD}\right)$, where $0<\mathrm{t}<1$.

Given $\mathrm{T}_{1}=\mathrm{i}$, high risk policyholders are fully insured, while low risk policyholders are partially insured. Each insurer earns zero profits. The outcome is depicted in Figure 1. Contracts are denoted by their corresponding wealth pairs in the figures throughout this paper.

Figure 1

Now, let us consider the case in which information asymmetry is present for general risks $\left(T_{1}\right)$, but not for specific risks $\left(T_{2}\right)$. In other words, insurers can observe both $T_{1}$ and $T_{2}$, while policyholders can only observe their own $T_{2}$. This the insurersided adverse selection situation is studied in Villeneuve $(2000,2005)$. Our case is different from Villeneuve (2000) in that we consider a competitive market while Villeneuve (2000) considers a monopolistic market. Villeneuve (2005) considers several different cases in a competitive market. Our treatment corresponds to the case in which the Intuitive Criterion of Cho and Kreps (1987) are used as an equilibrium refinement.

Since insurers with superior information offer contracts, this case can be described as a signaling game. We focus on the Perfect Bayesian Equilibrium (PBE) under competition. Given $\mathrm{T}_{2}=\mathrm{i}$, a PBE is a set of contracts $\left\{\mathrm{C}_{\mathrm{Hi}}, \mathrm{C}_{\mathrm{Li}}\right\}$ s.t. (i) $\mathrm{C}_{\mathrm{ki}}$ is a profit-maximizing contract to type $T_{1}=k$, given contracts offered by other insurers and the beliefs of policyholders, for $\mathrm{k}=\mathrm{H}, \mathrm{L}$; (ii) Beliefs about type $\mathrm{T}_{1}$ 's of policyholders are determined by the Bayes' rule whenever applicable. We also require that a PBE pass the Intuitive Criterion. ${ }^{2}$ Finally, we suppose that contracts offered can be

$P_{i L} U\left(W-D-\alpha_{i L}+\beta_{1 i L}\right)+\left(1-p_{1 i L}\right) U\left(W-\alpha_{i L}\right) \geq p_{i L} U\left(W-D-\alpha_{i H}+\beta_{i H}\right)+\left(1-p_{i L}\right) U(W-$ $\left.\alpha_{\mathrm{iH}}\right)$

$\mathrm{P}_{\mathrm{iH}} \mathrm{U}\left(\mathrm{W}-\mathrm{D}-\alpha_{\mathrm{iH}}+\beta_{\mathrm{iH}}\right)+\left(1-\mathrm{p}_{\mathrm{iH}}\right) \mathrm{U}\left(\mathrm{W}-\alpha_{\mathrm{iH}}\right) \geq \mathrm{p}_{\mathrm{iH}} \mathrm{U}\left(\mathrm{W}-\mathrm{D}-\alpha_{\mathrm{iL}}+\beta_{\mathrm{iL}}\right)+\left(1-\mathrm{p}_{\mathrm{iH}}\right) \mathrm{U}(\mathrm{W}-$ $\left.\alpha_{\mathrm{iL}}\right)$

${ }^{2}$ The Intuitive Criterion, in our context, can be stated as follows: Given an off-the- 
observed by all policyholders. Therefore, if an insurer offers a contract that is marginally preferred to other contracts by a type $T_{1}=k$, then all $\mathrm{kT}_{2}$-policyholders will purchase from the insurer. This assumption reflects the market competition, since an insurer that succeeds to provide $\mathrm{T}_{1}=\mathrm{k}$-policyholders with higher utilities than other insurers can take over the whole market for $\mathrm{T}_{1}=\mathrm{k}$-policyholders. This assumption also removes the possibility of collusion among insurers considered in Villeneuve (2005).

Analytically, separating equilibrium (PBE) contracts $\left\{\mathrm{C}_{\mathrm{Hi}}^{\mathrm{I}}, \mathrm{C}_{\mathrm{Li}}^{\mathrm{I}}\right\}$ will solve the following program, given $\mathrm{T}_{2}=\mathrm{i}$.

Program 3 [Insurer-sided adverse selection]:

$$
\begin{array}{ll}
\operatorname{Max}_{\{\mathrm{CHi}}, \mathrm{CLi}_{\}} \mathrm{V}\left(\mathrm{C}_{\mathrm{Li}}\right)=\mathrm{p}_{\mathrm{Li}} \mathrm{U}\left(\mathrm{W}-\mathrm{D}-\alpha_{\mathrm{Li}}+\beta_{\mathrm{Li}}\right)+\left(1-\mathrm{p}_{\mathrm{Li}}\right) \mathrm{U}\left(\mathrm{W}-\alpha_{\mathrm{Li}}\right) \\
\text { s.t. } \quad \pi\left(\mathrm{C}_{\mathrm{ki}}\right)=\alpha_{\mathrm{ki}}-\mathrm{p}_{\mathrm{ki}} \beta_{\mathrm{ki}} \geq 0, \text { for } \mathrm{k}=\mathrm{H}, \mathrm{L} . \\
& \pi\left(\mathrm{C}_{\mathrm{ki}}\right) \geq \pi\left(\mathrm{C}_{\mathrm{mi}}: \mathrm{ki}\right) \geq 0 \text { for } \mathrm{k}, \mathrm{m}=\mathrm{H}, \mathrm{L}, \text { and } \mathrm{k} \neq \mathrm{m} .{ }^{3} \\
& \mathrm{~V}\left(\mathrm{C}_{\mathrm{Hi}}\right) \geq \mathrm{V}(0 \text { : Hi }) .
\end{array}
$$

The first set of constraints describes the participation of insurers. The second set of constraints describes the self-selection for insurers regarding $T_{1}$. The third set of constraints describes the participation of policyholders.

Let us show that, at an optimum, the self-selection constraint for insurers regarding $\mathrm{T}_{1}=\mathrm{L}$ should be binding: $\alpha_{\mathrm{Li}}-\mathrm{p}_{\mathrm{Li}} \beta_{\mathrm{Li}}=\alpha_{\mathrm{Hi}}-\mathrm{p}_{\mathrm{Li}} \beta_{\mathrm{Hi}}$. Suppose not. If $\pi\left(C_{L i}^{I}\right)>0$, then there exists another contract $C_{L i}{ }^{a}$ with a slightly lower premium $\left(\alpha_{\mathrm{Li}}{ }^{a}\right)$ that can attract Li-policyholders without violating any other constraint, which is a contradiction. However, if $\pi\left(\mathrm{C}_{\mathrm{Li}}^{\mathrm{I}}\right)=0$, then the self-selection constraints and the assumption that $\mathrm{p}_{\mathrm{Hi}}>\mathrm{p}_{\mathrm{Li}}$ lead to the violation of nonnegative profits since $0=\alpha_{\mathrm{Li}}-$ $\mathrm{p}_{\mathrm{Li}} \beta_{\mathrm{Li}}>\alpha_{\mathrm{Hi}}-\mathrm{p}_{\mathrm{Li}} \beta_{\mathrm{Hi}} \geq \alpha_{\mathrm{Hi}}-\mathrm{p}_{\mathrm{Hi}} \beta_{\mathrm{Hi}}$. As a result, the self-selection constraint regarding $\mathrm{T}_{1}=\mathrm{L}$ should be binding.

Now, it is easy to see that $\pi\left(\mathrm{C}_{\mathrm{Li}}^{\mathrm{I}}\right)=0$ and $\pi\left(\mathrm{C}_{\mathrm{Hi}}^{\mathrm{I}}\right)=0$. Given any $\mathrm{C}_{\mathrm{Li}}^{\mathrm{I}}$, it is clear that $\mathrm{C}_{\mathrm{Hi}}^{\mathrm{I}}$ should give a zero profit due to competition. For example, if $\mathrm{C}_{\mathrm{Li}}^{\mathrm{I}}$ is $\mathrm{C}_{\mathrm{Li}}{ }^{0}$ in Figure 2, then competition induces insurers to offer $\mathrm{C}_{\mathrm{Hi}}{ }^{0}$ which provides a zero profit and is preferred by Hi-policyholders to any other contract, say $\mathrm{C}_{\mathrm{Hi}}{ }^{\mathrm{s}}$, with the selfselection constraint regarding $C_{L i}$ binding. Now, we argue that $\pi\left(C_{L i}^{I}\right)=0$. Suppose,

equilibrium contract, the beliefs of policyholders should put a zero probability to a type $\mathrm{T}_{1}=\mathrm{k}$, if the highest possible profit of the $\mathrm{T}_{1}=\mathrm{k}$-insurer generated by the contract is lower than the equilibrium profit.

${ }^{3}$ In detail, the constraints are: $\alpha_{\mathrm{Hi}}-\mathrm{p}_{\mathrm{Hi}} \beta_{\mathrm{Hi}} \geq \alpha_{\mathrm{Li}}-\mathrm{p}_{\mathrm{Hi}} \beta_{\mathrm{Li}}$, and $\alpha_{\mathrm{Li}}-\mathrm{p}_{\mathrm{Li}} \beta_{\mathrm{Li}} \geq \alpha_{\mathrm{Ki}}-\mathrm{p}_{\mathrm{Li}} \beta_{\mathrm{Ki}}$. 
on the contrary, that $\mathrm{C}_{\mathrm{Li}}^{\mathrm{I}}$ is $\mathrm{C}_{\mathrm{Li}}{ }^{0}$ s.t. $\pi\left(\mathrm{C}_{\mathrm{Li}}{ }^{0}\right)>0$ in Figure 2. If so, an insurer can attract Li-policyholders by offering a contract $\mathrm{C}_{\mathrm{Li}}{ }^{\mathrm{d}}$ that is located in the northeastern direction of $\mathrm{C}_{\mathrm{Li}}{ }^{0}$, accompanied by the corresponding change of the contract for Hi-policyholders from $\mathrm{C}_{\mathrm{Hi}}{ }^{0}$ to $\mathrm{C}_{\mathrm{Hi}}{ }^{\mathrm{d}}$ which provides a zero profit and keeps the self-selection incentive constraint regarding $\mathrm{T}_{1}=\mathrm{L}$ binding. We can find such $\mathrm{C}_{\mathrm{Hi}}{ }^{\mathrm{d}}$, whenever $\pi\left(\mathrm{C}_{\mathrm{Li}}{ }^{0}\right)>0$. Therefore, $\pi\left(\mathrm{C}_{\mathrm{Li}}^{\mathrm{I}}\right)=0$ in equilibrium. Eventually, competition induces insurers to offer full insurance to Li-policyholders: $\mathrm{C}_{\mathrm{Li}}^{\mathrm{I}}=\left(\mathrm{p}_{\mathrm{Li}} \mathrm{D}, \mathrm{D}\right) . \quad$ With $\pi\left(\mathrm{C}_{\mathrm{Li}}^{\mathrm{I}}\right)=0$, the only possible contract for Hi-policyholders is no insurance: $\mathrm{C}_{\mathrm{Hi}}^{\mathrm{I}}=(0,0)$. The results are summarized in Lemma 1.

Lemma 1: [Insurer-sided adverse selection]

In equilibrium, low-general-risk policyholders purchase actuarially fair full insurance, while high-general-risk policyholders purchase no insurance.

Figure 2

For completeness, we need to specify the off-equilibrium beliefs to support this equilibrium. The following belief supports the equilibrium: Each policyholder conjectures that his general-risk type is low $\left(\mathrm{T}_{1}=\mathrm{L}\right)$ if offered a contract off the equilibrium. It is easy to see that this belief passes the Intuitive Criterion. Finally, no pooling equilibrium can exist. For this, note that the expected profit should be zero under competition, implying that an insurer makes negative profits from high risk policyholders. An insurer will prefer to offer no insurance to high risk policyholders.

\section{Double-Sided Adverse Selection}

In this section, we synthesize models considered in the previous section. Now, we assume that insurers can only observe $T_{1}$ of policyholders, while policyholders can only observe their own $\mathrm{T}_{2}$. Therefore, insurers need to screen policyholders' information about $\mathrm{T}_{2}$ as well as signal information about $\mathrm{T}_{1}$. Contracts $\left\{\mathrm{C}^{*}{ }_{\mathrm{LL}}, \mathrm{C}^{*}{ }_{\mathrm{LH}}\right.$, $\left.\mathrm{C}^{*}{ }_{\mathrm{HL}}, \mathrm{C}^{*}{ }_{\mathrm{HH}}\right\}$ will solve the following program in equilibrium.

Program 4 [Double-sided adverse selection]:

$$
\begin{array}{ll}
\operatorname{Max}_{\{\mathrm{ClL}, \text { СLн, Снг, Снн }\}} V\left(\mathrm{C}_{\mathrm{LL}}\right) \quad \mathrm{p}_{\mathrm{LL}} \mathrm{U}\left(\mathrm{W}-\mathrm{D}-\alpha_{\mathrm{LL}}+\beta_{\mathrm{LL}}\right)+\left(1-\mathrm{p}_{\mathrm{LL}}\right) \mathrm{U}\left(\mathrm{W}-\alpha_{\mathrm{LL}}\right) \\
\text { s.t. } \quad \pi\left(\mathrm{C}_{\mathrm{km}}\right) \geq 0 \text { for } \mathrm{k}, \mathrm{m}=\mathrm{H}, \mathrm{L} . \\
& \pi\left(\mathrm{C}_{\mathrm{ks}}\right) \geq \pi\left(\mathrm{C}_{\mathrm{ms}} \text { : } \mathrm{ks}\right), \text { for } \mathrm{k}, \mathrm{m}, \mathrm{s}=\mathrm{H}, \mathrm{L}, \text { and } \mathrm{m} \neq \mathrm{k} .
\end{array}
$$




$$
\begin{aligned}
& \mathrm{V}\left(\mathrm{C}_{\mathrm{ks}}\right) \geq \mathrm{V}\left(\mathrm{C}_{\mathrm{km}}: \mathrm{ks}\right) \text {, for } \mathrm{k}, \mathrm{m}, \mathrm{s}=\mathrm{H}, \mathrm{L}, \text { and } \mathrm{m} \neq \mathrm{k} . \\
& \mathrm{V}\left(\mathrm{C}_{\mathrm{km}}\right) \geq \mathrm{V}(0: \mathrm{km})
\end{aligned}
$$

The first set of constraints describes the participation of insurers. The second set of constraints describes the self-selection for insurers regarding $\mathrm{T}_{1}$, and the third set of constraints describes the self-selection for policyholders regarding $T_{2}$. The final set of constraints describes the participation of policyholders.

Now, let us first characterize a separating equilibrium. In a separating equilibrium, insurers offer the high-general-risk $\left(\mathrm{T}_{1}=\mathrm{H}\right)$ policyholders the menu of $\left\{\mathrm{C}^{*}{ }_{\mathrm{HH}}, \mathrm{C}^{*}{ }_{\mathrm{HL}}\right\}$ while they offer the low-general-risk $\left(\mathrm{T}_{1}=\mathrm{L}\right)$ policyholders the menu of $\left\{\mathrm{C}^{*}{ }_{\mathrm{LH}}, \mathrm{C}^{*}{ }_{\mathrm{LL}}\right\}$. First of all, it is clear that in equilibrium each contract should break even due to competition (see Lemma 1). If we consider each $\mathrm{T}_{1}$ in isolation, the outcomes would be full insurance for $T_{1} H$ and partial insurance for $T_{1} L$ as in the policyholder-sided adverse selection case. Now, however, the insurer should also take into account the self-selection constraints for insurers regarding $T_{1}=L$ for each $T_{2}$. Lemma 1 implies that insurers will offer no insurance to $\mathrm{HT}_{2}$ for each $\mathrm{T}_{2}$. Therefore, $\mathrm{C}^{*}{ }_{\mathrm{HH}}=\mathrm{C}^{*}{ }_{\mathrm{HL}}=0$. Given this result, the problem reduces to the policyholder-sided adverse selection case with $\mathrm{T}_{1}=\mathrm{L}$, leading to Rothschild and Stiglitz outcomes for $\mathrm{LH}$ and LL. This equilibrium is depicted in Figure 3, in which $\mathrm{C}^{*}{ }_{\mathrm{HH}}=\mathrm{C}^{*}{ }_{\mathrm{HL}}=0 ; \mathrm{C}^{*}{ }_{\mathrm{LH}}=$ $\mathrm{C}_{\mathrm{LH}}^{\mathrm{P}}=\left(\mathrm{p}_{\mathrm{LH}} \mathrm{D}, \mathrm{D}\right), \mathrm{C}^{*}{ }_{\mathrm{LL}}=\mathrm{C}_{\mathrm{LL}}^{\mathrm{P}}=\left(\mathrm{p}_{\mathrm{LL}} \mathrm{tD}, \mathrm{tD}\right), 0<\mathrm{t}<1$.

Figure 3

Finally, we need to specify the off-the-equilibrium beliefs to support this equilibrium. Similar to the insurer-sided adverse selection case, the following belief supports the equilibrium and passes the Intuitive Criterion: Each policyholder conjectures that his general-risk type is low $\left(\mathrm{T}_{1}=\mathrm{L}\right)$ if offered a contract off the equilibrium. The non-existence of pooling equilibrium is easily obtained, since there would be profitable contracts attracting low-specific-risk policyholders (see Rothschild and Stiglitz, 1976). The results are summarized in Proposition 1.

Proposition 1: [Double-sided adverse selection]

In equilibrium;

(i) Among low-general-risk policyholders, low-specific-risk policyholders purchase partial insurance while high-specific-risk policyholders purchase full insurance as in Rothschild and Stiglitz (1976). All contracts are actuarially fair. 
(ii) High-general-risk policyholders purchase no insurance.

The results have interesting implications that deserve to be mentioned. First, insurers are cream-skimming since they offer contracts only to low-general-risk policyholders. Even with the screening and signaling devices that are considered as (at least partial) solutions to adverse selection problems, our results are similar to the no-device-case as in Akerlof (1970) in that only extreme markets are open. Our results, however, are also in contrast with Akerlof (1970) in that the high quality (low risk) market is open in our case, while the lemons (high risk) market is open in Akerlof.

Second, unlike in the standard adverse selection literature, the relationship between insurance purchases and risk types is not in one direction. Higher risk policyholders may be more or less insured than lower risk policyholders. The highest risk (HH-) policyholders are not insured and the lowest risk (LL-) policyholders are partially insured. However, in the range of medium risks, the results depend on the relative sizes of $\mathrm{p}_{\mathrm{LH}}$ and $\mathrm{p}_{\mathrm{HL}}$. If $\mathrm{p}_{\mathrm{LH}} \leq \mathrm{p}_{\mathrm{HL}}$, then high risk (HL-) policyholders are not insured, while low risk (LH-) policyholders are fully insured. On the other hand, if $\mathrm{p}_{\mathrm{HL}} \leq \mathrm{p}_{\mathrm{LH}}$ as in Figure 3, then high risk (LH-) policyholders fully insured, while low risk (HL-) policyholders are not insured. The lesson is that the relationship between insurance purchases and risk types is not in one direction under information asymmetry.

Corollary 1: [Double-sided adverse selection]

The relationship between insurance purchases and risk types is not in one direction.

\section{Publicizing Information}

Since insurers cannot sell insurance to high general risks when the insurer-sided adverse selection problem exists, they have strong incentives to reveal their information. Suppose that there is technology to publicize their information. We assume that the technology is not necessarily perfect, so that it reports $\mathrm{R}^{\mathrm{k}}$ with probability $\mathrm{S}$ or $\mathrm{R}^{\mathrm{m}}$ with probability 1-S, when the true $\mathrm{T}_{1}$ is $\mathrm{k}$ : $\operatorname{Pr}$. (report $=\mathrm{R}^{\mathrm{k}} \mid \mathrm{T}_{1}=\mathrm{k}$ ) $=\mathrm{S}$, Pr. (report $=\mathrm{R}^{\mathrm{m}} \mid \mathrm{T}_{1}$ $=\mathrm{k})=1-\mathrm{S}$ for $\mathrm{k}, \mathrm{m}=\mathrm{H}, \mathrm{L}$, and $\mathrm{k} \neq \mathrm{m}$. For example, a health insurer may publicize its underwriting rule based on the health examination reports observable both by the insurer and policyholders. Since policyholders can observe how insurance premium is determined based on the public information, the underwriting rule can work as a publicizing technology. Another example is that an automobile insurer publicizes its pricing rules based on policyholders' characteristics such as age and types of 
automobiles. $^{4}$ Note that these publicizing technologies are widely used in the internet where price quotes are provided by agents and insurers. This technology is distinguished from categorization in that informed agents, instead of uninformed agents, try to reveal information.

Let us assume that all insurers are forced to publicize information and commit to follow the publicized information. Define $\mathrm{p}_{\mathrm{km}}$ ' as the perceived risk of a km'policyholder or a $T_{2}=m$-policyholder who receives report $R^{k}$. We have $p_{H m}{ }^{\prime}=\rho_{H} \cdot p_{H m}$ $+\left(1-\rho_{\mathrm{H}}\right) \cdot \mathrm{p}_{\mathrm{Lm}}$ and $\mathrm{p}_{\mathrm{Lm}}{ }^{\prime}=\rho_{\mathrm{L}} \cdot \mathrm{p}_{\mathrm{Lm}}+\left(1-\rho_{\mathrm{L}}\right) \cdot \mathrm{p}_{\mathrm{Hm}}$, where $\rho_{\mathrm{H}}=\frac{S a}{S a+(1-S)(1-a)}, \rho_{\mathrm{L}}$ $=\frac{S(1-a)}{(1-S) a+S(1-a)}$, and $a$ is the proportion of $\mathrm{T}_{1}=\mathrm{H}$-policyholders. Based on the reports of the technology, policyholders categorize their own risks into $\left\{\mathrm{p}_{\mathrm{HH}}{ }^{\prime}, \mathrm{p}_{\mathrm{HL}}{ }^{\prime}, \mathrm{p}_{\mathrm{LH}}\right.$, $\mathrm{p}_{\mathrm{LL}}{ }^{\prime}{ }^{5} .^{5}$ When $\mathrm{S}=1$, the technology perfectly reveals the information. When $\mathrm{S}=0$, the situation corresponds to the double-sided adverse selection case. Note that $\mathrm{p}_{\mathrm{Hm}} \geq$ $\mathrm{p}_{\mathrm{Hm}}{ }^{\prime}$ and $\mathrm{p}_{\mathrm{Lm}} \leq \mathrm{p}_{\mathrm{Lm}}$. In words, $\mathrm{T}_{1}=\mathrm{H}$-policyholders underestimate their risks, while $\mathrm{T}_{1}=\mathrm{L}$-policyholders overestimate their risks. Let us focus on imperfect technology, i.e., $0<\mathrm{S}<1$.

Since insurers commit to follow the technology reports, there is no need to consider the insurer-sided adverse selection problem. Therefore, equilibrium outcomes are two menus of contracts, each of which is determined similarly as in Rothschild and Stiglitz (1976). In equilibrium, each contract should break even, implying that insurance premium is based on $\mathrm{p}_{\mathrm{Hm}}$ ' and $\mathrm{p}_{\mathrm{Lm}}{ }^{\prime}$. Equilibrium contracts are denoted by $\mathrm{C}_{\mathrm{HH}}, \mathrm{C}_{\mathrm{HL}}{ }^{\prime}, \mathrm{C}_{\mathrm{LH}}$, and $\mathrm{C}_{\mathrm{LL}}$ ' in Figure 4. $\mathrm{HH}$ - and $\mathrm{LH}^{\prime}$ - policyholders are fully insured and HL'- and LL'-policyholders are partially insured. The results are summarized in Lemma 2.

Lemma 2: [Mandatory publicizing of information]

Suppose that insurers are forced to publicize information and commit to follow the publicized information. We assume that the publicizing technology is not perfect. (i) In equilibrium, HH'- and LH'-policyholders purchase full insurance, while HL'- and LL'-policyholders purchase partial insurance.

\footnotetext{
4 These underwriting and pricing rules are not perfect as long as the public information does not perfectly represent the general risks of policyholders.

${ }^{5}$ One tricky issue is that policyholders can contact many insurers to obtain good publicized information, since obtaining publicized information does not incur any costs in our model. To circumvent this issue, we assume that publicized information is the same for all insurers or that insurers use the common publicized information.
} 
(ii) Contracts are actuarially fair based on perceived risks.

Figure 4

Some comments deserve to be mentioned. First, it is important to note that the commitment of insurers is critical for the results. The publicizing technology, unless $\mathrm{S}$ $=1$, does not completely remove information asymmetry, since insurers still possess superior information regarding $\mathrm{T}_{1}$. If insurers do not commit to follow the reports, they will prefer to offer no insurance to $\mathrm{T}_{1}=\mathrm{H}$-policyholders, since $\mathrm{C}_{\mathrm{HH}}$ and $\mathrm{C}_{\mathrm{HL}}$ ' make losses when offered to HH- and HL-policyholders. Therefore, the above result cannot be obtained. Commitment can be obtained by sticking to publicized underwriting rules. For example, direct marketing and underwriting through the internet can be used as a commitment device.

Second, a mandatory introduction of the publicizing technology has ambiguous effects on efficiency. On the one hand, efficiency gains are obtained by opening a market for high-general-risk policyholders. On the other hand, low-general-risk policyholders suffer utility losses. The net effects are not clear.

Now, let us change the assumption of mandatory publicizing of information. Instead, suppose that insurers are allowed to opt to publicize information. We argue that some insurers publicize information and others do not in equilibrium, if it exists. For, if all insurers publicize their information, then an insurer that opt not to publicize will attract all $\mathrm{T}_{1}=\mathrm{L}$-policyholders by offering $\mathrm{C}^{*}{ }_{\mathrm{Li}}$, since the policyholders prefer $\mathrm{C}_{\mathrm{Li}}$ to $\mathrm{C}_{\mathrm{Li}}{ }^{\prime}$ for $\mathrm{T}_{2}=\mathrm{i}$. On the other hand, if no insurers publicize their information, then an insurer that opts to publicize information will attract all $\mathrm{T}_{1}=\mathrm{H}$-policyholders, since they prefer $\mathrm{C}_{\mathrm{H} 2}$ to no insurance. Therefore, in equilibrium, if it exists, some insurers publicize information, while others do not.

Now, let us characterize equilibrium contracts. First, note that insurers that do not publicize information will offer $\left\{\mathrm{C}^{*}{ }_{\mathrm{HH}}=0, \mathrm{C}^{*}{ }_{\mathrm{HL}}=0\right\}$ and $\left\{\mathrm{C}^{*}{ }_{\mathrm{LH}}=\mathrm{C}_{\mathrm{LH}}^{\mathrm{P}}, \mathrm{C}^{*}{ }_{\mathrm{LL}}=\right.$ $\mathrm{C}_{\mathrm{LH}}^{\mathrm{P}}$ as in the previous section. Suppose that insurers that publicize information offer $\left\{\mathrm{C}_{\mathrm{HH}}{ }^{\prime}, \mathrm{C}_{\mathrm{HL}}{ }^{\prime}\right\}$ and $\left\{\mathrm{C}_{\mathrm{LH}}, \mathrm{C}_{\mathrm{LL}}{ }^{\prime}\right\}$, where each contract should break even. $\mathrm{T}_{1}=\mathrm{H}-$ policyholders will purchase from insurers that publicize information, since they prefer $\left\{\mathrm{C}_{\mathrm{HH}}, \mathrm{C}_{\mathrm{HL}}\right.$ ' $\}$ to no insurance. This implies that $\mathrm{T}_{1}=\mathrm{L}$-policyholders should prefer $\left\{\mathrm{C}^{*}{ }_{\mathrm{LH}}, \mathrm{C}^{*}{ }_{\mathrm{LL}}\right\}$ to $\left\{\mathrm{C}_{\mathrm{LH}}{ }^{\prime}, \mathrm{C}_{\mathrm{LL}}{ }^{\prime}\right\}$, since $\mathrm{p}_{\mathrm{Lm}} \leq \mathrm{p}_{\mathrm{Lm}}{ }^{\prime}{ }^{6}{ }^{6}$ Thus, $\mathrm{T}_{1}=\mathrm{L}$-policyholders do not

${ }^{6}$ In fact, there is a possibility that LL-policyholders prefer to purchase from insurers that publicize information even if $\mathrm{p}_{\mathrm{LL}} \leq \mathrm{p}_{\mathrm{LL}}$, since $\mathrm{C}_{\mathrm{LL}}^{*}$ is a partial insurance. 
purchase from insurers that publicize information. As a result, Lm-policyholders purchase $\mathrm{C}_{\mathrm{Lm}}$ from insurers that do not publicize information, while Hm-policyholders purchase $\mathrm{C}_{\mathrm{Hm}}{ }^{\prime}$ from insurers that publicize information. ${ }^{7}$ Given this separation, $\mathrm{p}_{\mathrm{Hm}}{ }^{\prime}=$ $\mathrm{p}_{\mathrm{Lm}}{ }^{\prime}=\mathrm{p}_{\mathrm{Hm}} \cdot{ }^{8} \quad$ Thus, $\mathrm{C}_{\mathrm{HH}}{ }^{\prime}=\mathrm{C}_{\mathrm{LH}}{ }^{\prime}=\mathrm{C}_{\mathrm{HH}}^{\mathrm{P}}$ and $\mathrm{C}_{\mathrm{HL}}{ }^{\prime}=\mathrm{C}_{\mathrm{LL}}{ }^{\prime}=\mathrm{C}_{\mathrm{HL}}^{\mathrm{P}}$, which are depicted in Figure 5.

Figure 5

This result is exactly the same as if the insurer-sided adverse selection problem does not exist: $\mathrm{T}_{1}=\mathrm{H}$-policyholders purchase from $\left\{\mathrm{C}^{\mathrm{P}}{ }_{\mathrm{HH}}, \mathrm{C}^{\mathrm{P}}{ }_{\mathrm{HL}}\right\}$ from insurers that publicize information while $\mathrm{T}_{1}=\mathrm{L}$-policyholders purchase from $\left\{\mathrm{C}_{\mathrm{LH}}^{\mathrm{P}}, \mathrm{C}_{\mathrm{LL}}^{\mathrm{P}}\right\}$ from insurers that do not publicize information. Each insurer faces the policyholder-sided adverse selection case as in Rothschild and Stiglitz (1976).

Another important implication of the result is that there exist clientele relationships, since $T_{1}$-policyholders are separated by their preferred insurers. The clientele relationships are observed such that high-general-risk policyholders purchase from insurers with publicized and standardized underwriting rules, while low-generalrisk policyholders purchase from insurers with non-publicized or non-standardized underwriting rules.

Note that efficiency is unambiguously enhanced by allowing insurers to opt to publicize information, since $\mathrm{T}_{1}=\mathrm{H}$-policyholders are better off and $\mathrm{T}_{1}=\mathrm{L}$ policyholders remain the same. Finally, along with Corollary 1, the relationship between insurance purchases and risk types is not in one direction. Therefore, the empirical finding of no correlation between the insurance demand and risk types may imply the double-sided adverse selection problem instead of no adverse selection

However, we can show that this case cannot occur in equilibrium. Suppose that LLpolicyholders, not LH-policyholders, purchase from insurers that publicize information. In this case, insurers that publicize have incentives to offer full insurance, since no LHpolicyholders purchase from them. This full insurance, however, will also attract LHpolicyholders. As a result, once LL-policyholders purchase from insures that publicize information, LH-policyholders also purchase from them. However, if both policyholders purchase from the same type of insurers, then the insurers should offer separating contracts which, in turn, lead LH-policyholders to prefer to purchase from insurers that do not publicize information.

${ }^{7}$ High-general-risk policyholders are rejected by insurers that do not publicize information, thus purchase from insurers that publicize information. Low-general-risk policyholders are accepted by, and thus purchase from insurers that do not publicize information.

8 This result is obtained by substituting $a$ with 1 in $\rho_{\mathrm{H}}$ and $\rho_{\mathrm{L}}$. 
problem (see Chiappori 2000). When a one-sided adverse selection problem is to be investigated, the other-sided adverse selection problem should be controlled. The results are summarized in Proposition 2.

Proposition 2: [Strategic publicizing of information]

Suppose that insurers can strategically opt to publicize information.

(i) Given each general risk, low-specific-risk policyholders purchase partial insurance and high-specific-risk policyholders purchase full insurance as in Rothschild and Stiglitz (1976). Each contract is actuarially fair based on true risks.

(ii) [Clientele relationship] High-general-risk policyholders purchase from insurers that publicize information, while low-general-risk policyholders purchase from insurers that do not publicize information.

(iii) Efficiency is improved by the strategic publicization of information.

(iv) The relationship between insurance purchases and risk types is not in one direction.

\section{Multiple-Risk Cases}

Now, let us extend our model to more diverse risk cases. Suppose that there are $\mathrm{N}$ general-risk types $\left(\mathrm{T}_{1}=\mathrm{T}_{1}{ }^{1}, \ldots, \mathrm{T}_{1}{ }^{\mathrm{N}}\right)$ and $\mathrm{M}$ specific-risk types $\left(\mathrm{T}_{2}=\mathrm{T}_{2}{ }^{1}, \ldots, \mathrm{T}_{2}{ }^{\mathrm{M}}\right)$, where a higher superscript implies a higher risk: $\mathrm{T}_{\mathrm{h}}{ }^{\mathrm{i}}<\mathrm{T}_{\mathrm{h}}{ }^{\mathrm{j}}$ if $\mathrm{i}<\mathrm{j} . \quad$ Ignoring general risk types, the model is the same as the multiple-risk version of Rothschild and Stiglitz (1976) model. Therefore, the following holds for each $\mathrm{T}_{1}=\mathrm{k}$ in equilibrium: (i) each contract breaks even $\pi\left(\mathrm{C}_{\mathrm{kT} 2}{ }^{\mathrm{i}}\right)=0$; (ii) the highest specific risk policyholders are fully insured and others are partially insured; $\mathrm{C}_{\mathrm{kT} 2}{ }^{\mathrm{M}}=\left(\mathrm{p}_{\mathrm{kT} 2}{ }^{\mathrm{M}} \mathrm{L}, \mathrm{L}\right)$ and $\mathrm{C}_{\mathrm{kT} 2}{ }^{\mathrm{i}}=\left(\mathrm{p}_{\mathrm{kT} 2}{ }^{\mathrm{i}} \mathrm{t}^{\mathrm{i}} \mathrm{L}, \mathrm{t}^{\mathrm{i}} \mathrm{L}\right)$, where $0<\mathrm{t}^{\mathrm{i}}<1$, and (iii) a policyholder is indifferent between his own contract and a contract for a policyholder with the next highest risk; $\mathrm{EU}\left(\mathrm{C}_{\mathrm{kT}_{2}}{ }^{\mathrm{i}}\right)=\mathrm{EU}\left(\mathrm{C}_{\mathrm{kT}_{2}}{ }^{\mathrm{i}-1}: \mathrm{kT}_{2}{ }^{\mathrm{i}}\right)$.

Now, to take into account the insurer-sided adverse selection problems, let us first consider two lowest general risk types, $\mathrm{T}_{1}{ }^{1}$ - and $\mathrm{T}_{1}{ }^{2}$-policyholders. Similarly as in the previous section, self-selection constraints for insurers lead to the result that $\mathrm{T}_{1}{ }^{2}$ policyholders are offered no insurance. This leads to no insurance for all $\mathrm{T}_{1}{ }^{\mathrm{i}}$ policyholders, where $i \geq 2$, since self-selection constraints for insurers also imply that no insurance for $\mathrm{T}_{1}{ }^{\mathrm{n}}$-policyholders results in no insurance for $\mathrm{T}_{1}{ }^{\mathrm{n}+1}$-policyholders. As a result, in equilibrium, (i) $\mathrm{T}_{1}{ }^{1}$-policyholders are offered and purchase from $\left\{\mathrm{C}_{\mathrm{T}_{1}}{ }^{1} \mathrm{~T}_{2}{ }^{1}\right.$,

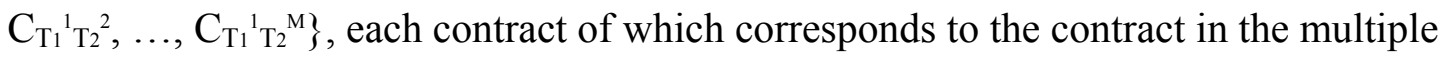
risk version of Rothschild and Stiglitz; and (ii) $\mathrm{T}_{1}{ }^{\mathrm{i}}$-policyholders, for $\mathrm{i} \geq 2$, purchase no 
insurance.

When insurers are allowed to strategically opt to publicize information, the following outcomes are obtained. Some insurers do not publicize information and offer contracts of the multiple-risk version of Rothschild and Stiglitz attracting $\mathrm{T}_{1}{ }^{1}$ policyholders only. Contracts for policyholders with $\mathrm{T}_{1} \neq \mathrm{T}_{1}{ }^{1}$ are zero. Contracts are based on true risks of policyholders. Other insurers publicize information and offer contracts of the multiple-risk version of Rothschild and Stiglitz for each reported general risk, attracting policyholders other than $\mathrm{T}_{1}{ }^{1}$-policyholders. By the same logic as in the previous section, we have that contracts for km'-policyholders are based on $\mathrm{p}_{\mathrm{km}}$ ' that is the average of the risks of $\mathrm{T}_{2}=\mathrm{m}$-policyholders who receive $\mathrm{R}^{\mathrm{k}}$, excluding $\mathrm{T}_{1}{ }^{1}$-policyholders. ${ }^{9} \quad$ In equilibrium, we find similar results as in the previous section: a clientele relationship and efficiency improvement. The results are summarized in Corollary 2. We omit the proof since the results are easily obtained by applying the same logic as in the previous sections.

Corollary 2: [Double-sided adverse selection under multiple-risk cases]

(i) Suppose that publicizing technology is not available. In equilibrium, the lowestgeneral-risk policyholders purchase insurance. Among these policyholders, contracts for different specific-risk policyholders are determined as in the multiple-risk version of Rothschild and Stiglitz. All other policyholders whose general risk types are not the lowest purchase no insurance.

(ii) Suppose that insurers can opt to publicize information.

(iia) [Clientele relationship] The lowest-general-risk policyholders purchase insurance from insurers that do not publicize information, while policyholders other than the lowest-general-risk policyholders purchase insurance from insurers that publicize information.

(iib) Among the lowest-general-risk policyholders, contracts for different specific-risk policyholders are determined as in the multiple-risk version of Rothschild and Stiglitz. Each contract is actuarially fair based on true risks.

(iic) Among the policyholders other than the lowest-general-risk policyholders, given each publicized general risk, contracts for different specific-risk policyholders are determined as in the multiple-risk version of Rothschild and Stiglitz, based on perceived risks. Each contract is actuarially fair based on perceived risks.

(iid) Efficiency is improved by the strategic publicizing of information.

${ }^{9}$ When all insurers are forced to publicize information, then contracts are based on the risks that are averaged across all $\mathrm{T}_{1}$-policyholders including $\mathrm{T}_{1}{ }^{1}$-policyholders. 


\section{Conclusion}

In existing adverse selection models, one party of an insurance contract is considered to possess superior information about risks to its counterparty (Rothschild and Stiglitz, 1976; Dionne, Doherty, and Fombaron, 2000; Villeneuve, 2000, 2005). In reality, however, each party of an insurance contract may have superior information about some part of risks to the other. These observations imply that the consideration of double-sided adverse selection will provide a more realistic understanding of insurance markets. This paper attempts to understand the outcomes when each party of the insurance contracts simultaneously has superior information to the other. We decompose the risk (probability of loss) of a policyholder into a general risk and a specific risk. We assume that policyholders have superior information about specific risks while insurers have superior information about general risks. Based on this assumption, we derive the equilibrium outcomes in competitive insurance markets where insurers try to signal their information, as well as they need to screen policyholders.

Our findings are as follows. When each risk can be either high or low, lowgeneral-risk policyholders purchase insurance, while high-general-risk policyholders are self-insured. Among the low-general-risk policyholders, high-specific-risk policyholders purchase full insurance, while low-specific-risk policyholders purchase partial insurance. We also investigate the role of publicizing information. When insurers can strategically use technology to publicize their information, efficiency is unambiguously improved, since high-general-risk policyholders purchase insurance. We find a clientele relationship: Low-general-risk policyholders purchase insurance from insurers that do not publicize information, while high-general-risk policyholders purchase from insurers that publicize information.

When our model is extended to multiple-risk cases, the lowest-general-risk policyholders purchase insurance, while other policyholders are self-insured. Among the lowest-general-risk policyholders, the highest-specific-risk policyholders purchase full insurance, while other policyholders purchase partial insurance. When insurers can strategically use technology to publicize their information, a clientele relationship still holds: The lowest-general-risk policyholders purchase insurance from insurers that do not publicize information, while other policyholders purchase from insurers that publicize information. As a result, efficiency is improved, since high-general-risk policyholders purchase insurance. 
One interesting implication of our results is that the relationship between risks and insurance demands is not in one direction, unlike in the standard adverse selection literature. As a result, no correlations between risks and insurance demands can be compatible with the existence of adverse selection. 
Figure 1: Policyholder-sided adverse selection

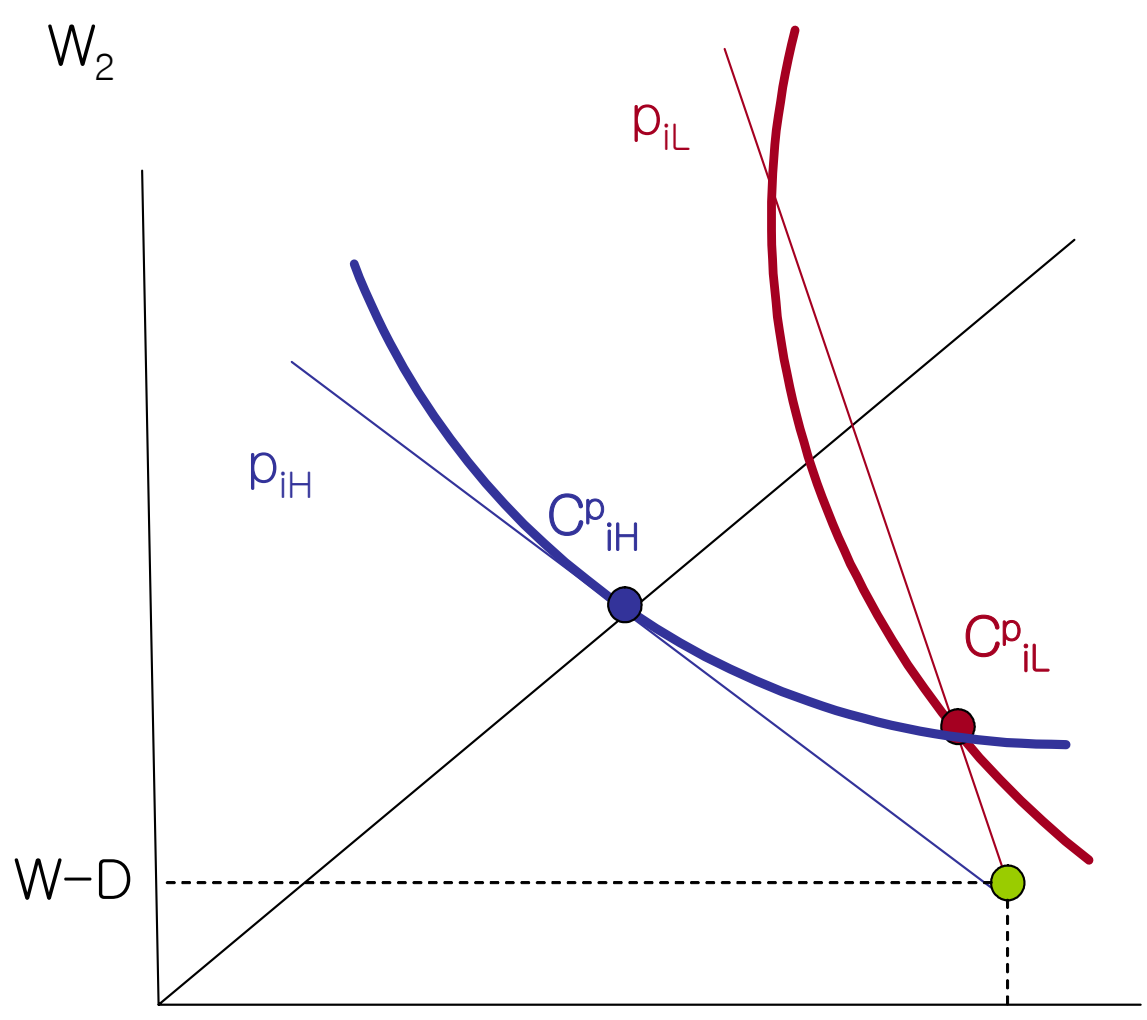


Figure 2: Insurer-sided adverse selection

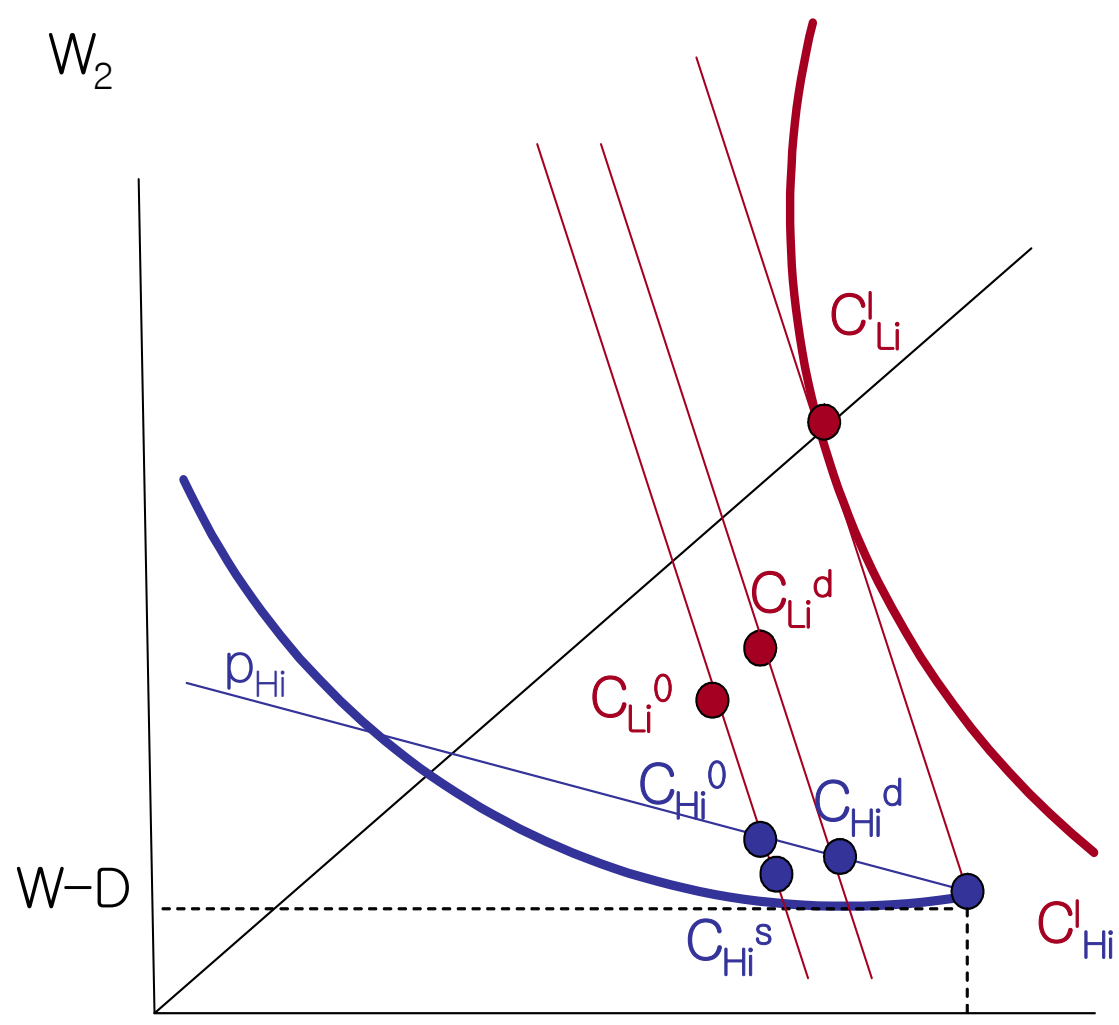

W 
Figure 3: Double-sided adverse selection

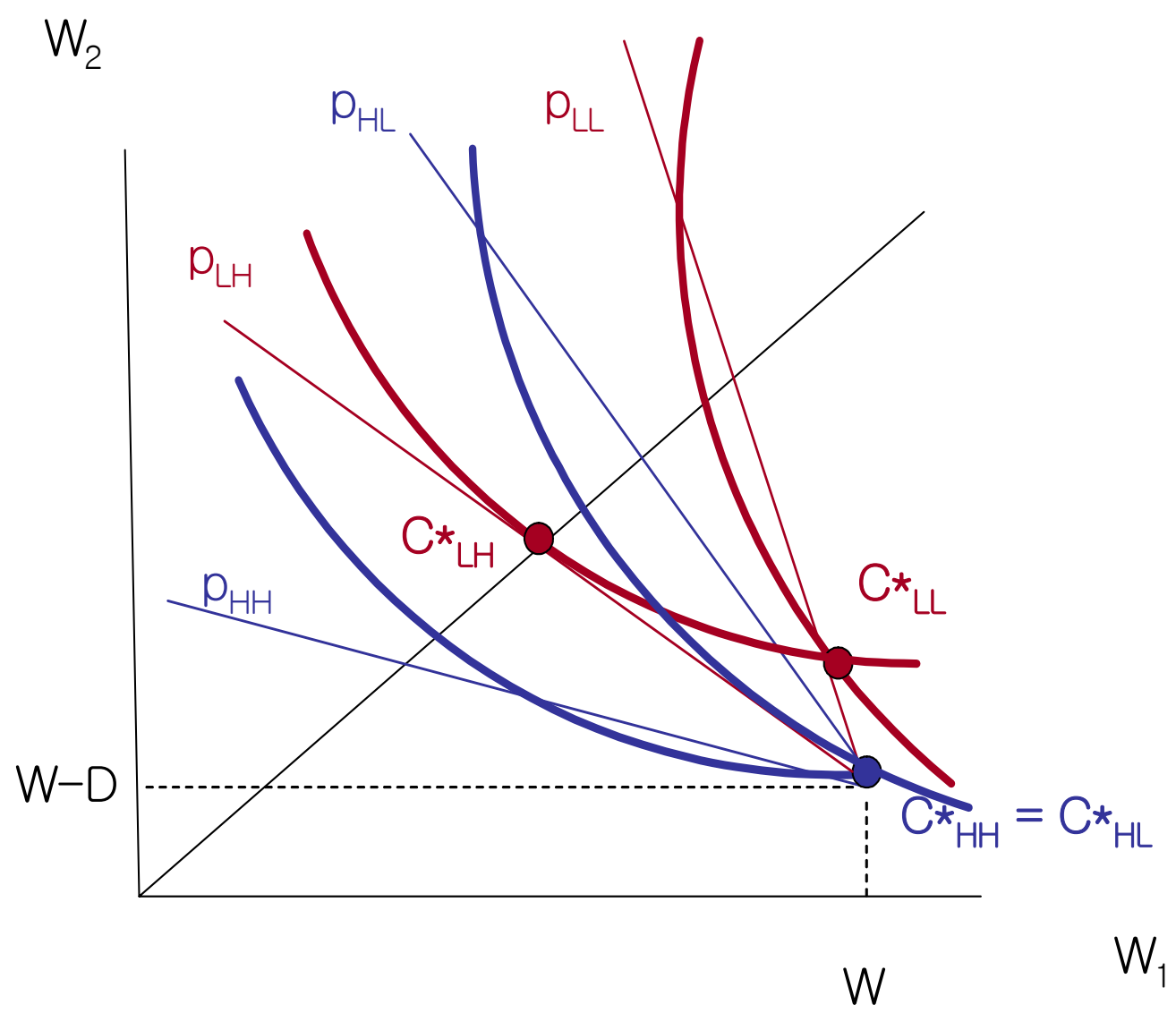


Figure 4: Mandatory publicizing of Information

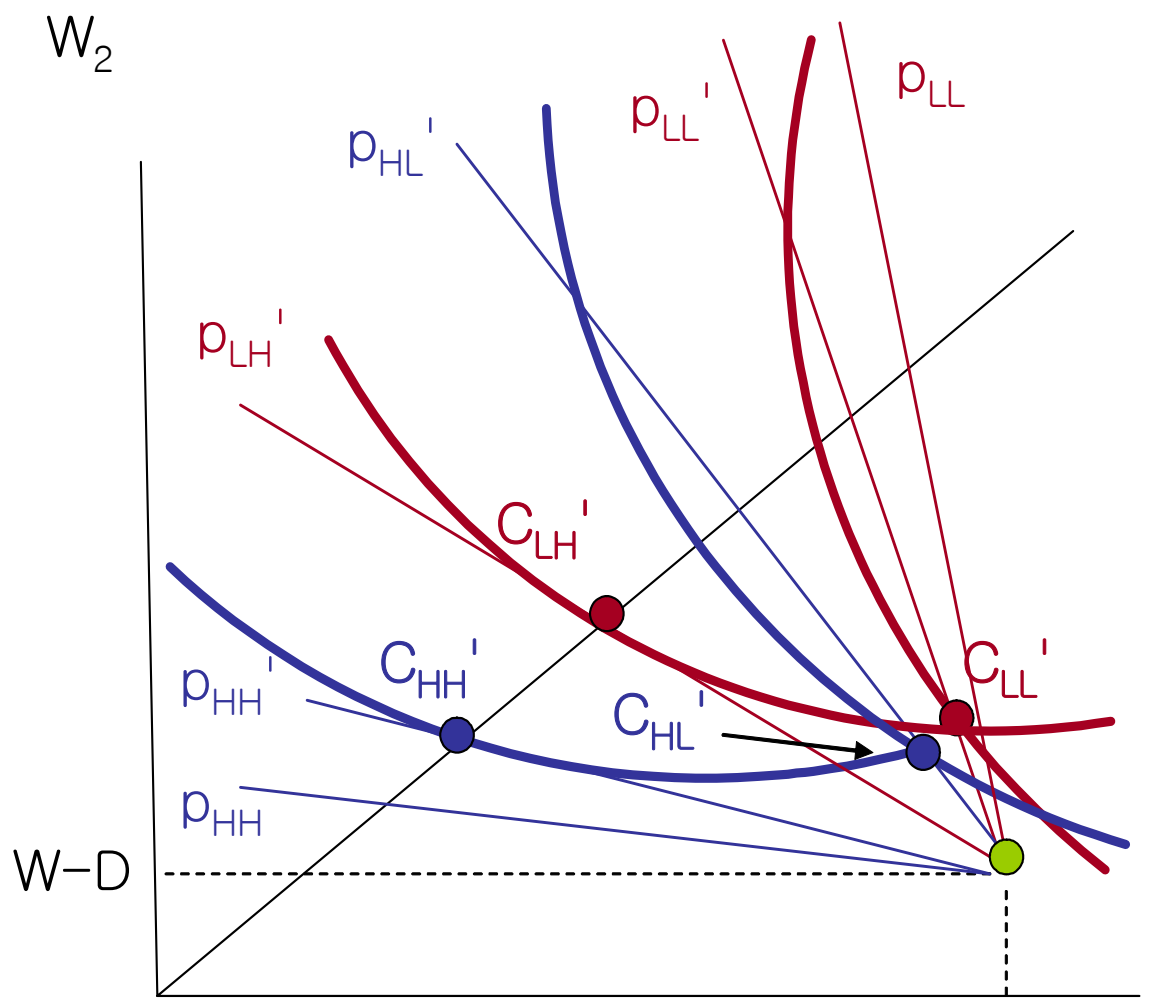


Figure 5: Strategic Publicizing of Information

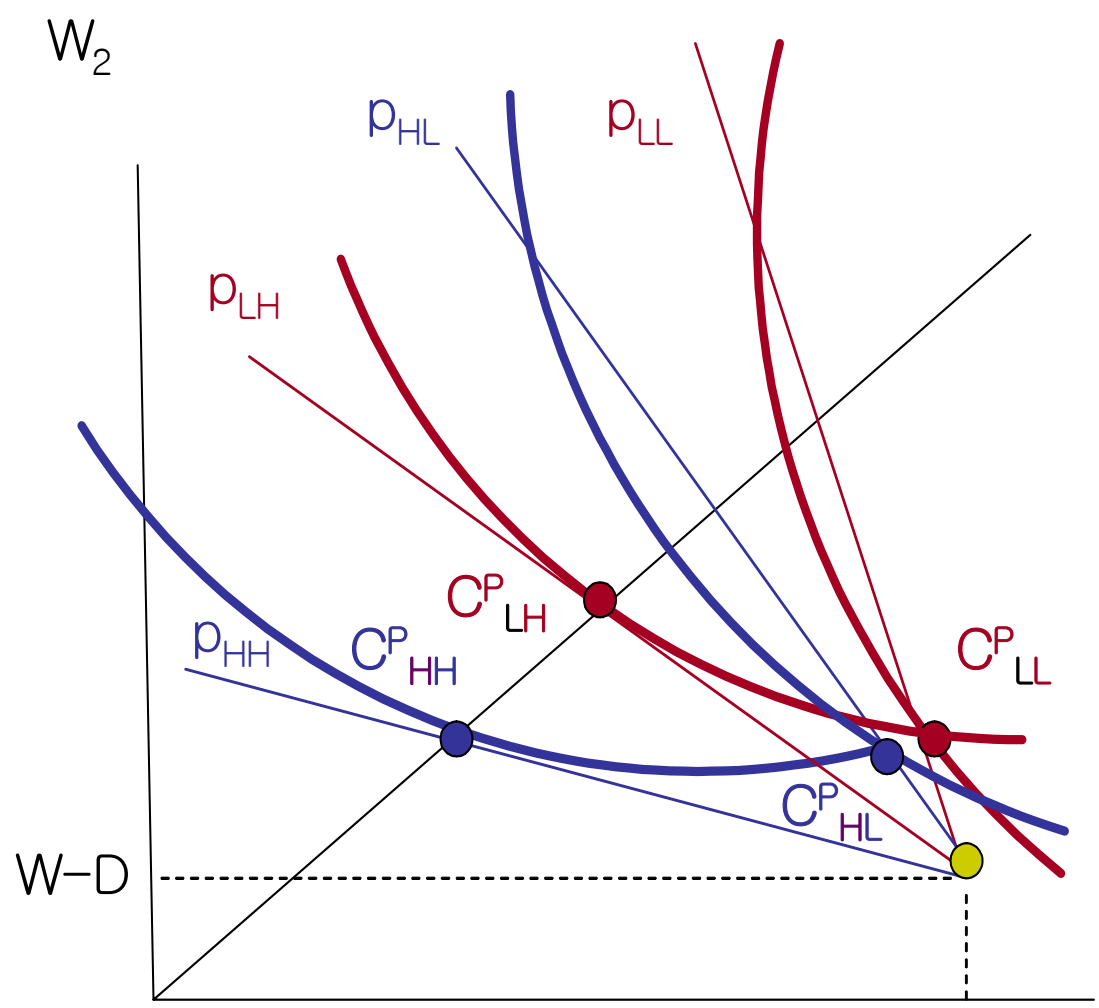

W 
References

Akerlof, George A., 1970, The Market for "Lemons": Quality Uncertainty and the Market Mechanism, Quarterly Journal of Economics 84: 488-500.

Chiappori, Pierre-Andre, 2000, Chapter 11 Econometric Models of Insurance under Asymmetric Information, Handbook of Insurance, edited by G. Dionne, Kluwer Academic Publishers, Boston/Dordrecht/London.

Cho, I.-K. and D. M. Kreps, 1987, Signaling Games and Stable Equilibria, Quarterly Journal of Economics 102: 179-221.

Dionne, G., N. Doherty, and N. Fombaron, 2000, Chapter 7 Adverse Selection in Insurance Markets, Handbook of Insurance, edited by G. Dionne, Kluwer Academic Publishers, Boston/Dordrecht/London.

Rothschild, M. and J. Stiglitz, 1976, Equilibrium in Competitive Insurance Markets: An Essay on the Economics of Imperfect Information, Quarterly Journal of Economics 90: 629-650.

Villeneuve, B., 2000, The Consequences for a Monopolistic Insurance Firms of Evaluating Risk Better than Customers: The Adverse Selection Hypothesis Reversed, Geneva Papers on Risk and Insurance Theory 25: 65-79.

Villeneuve, B., 2005, Competition between Insurers with Superior Information, European Economic Review 49: 321-340. 